Author affiliations and support information (if applicable) appear at the end of this article.

Published at jco.org on May 22, 2018.

Processed as a Rapid Communication manuscript.

Corresponding author: Dirk De Ruysscher $\mathrm{MD}, \mathrm{PhD}$, Department of Radiation Oncology, Maastro Clinic, Maastricht University Medical Center, Dr Tanslaan 12, NL-6229 ET Maastricht, The Netherlands; e-mail: dirk.deruysscher@ maastro.nl.

(C) 2018 by American Society of Clinical Oncology

$0732-183 X / 18 / 3623 w-2366 w / \$ 20.00$

\title{
Prophylactic Cranial Irradiation Versus Observation in Radically Treated Stage III Non-Small-Cell Lung Cancer: A Randomized Phase III NVALT-11/DLCRG-02 Study
}

Dirk De Ruysscher, Anne-Marie C. Dingemans, John Praag, Jose Belderbos, Caroline Tissing-Tan, Judith Herder, Tjeerd Haitjema, Fred Ubbels, Frank Lagerwaard, Sherif Y. El Sharouni, Jos A. Stigt, Egbert Smit, Harm van Tinteren, Vincent van der Noort, and Harry J.M. Groen

\section{$\begin{array}{llllllll}\text { A } & \text { B } & \text { S } & \text { T } & \text { R } & \text { A } & \text { C } & \text { T }\end{array}$}

\section{Purpose}

The purpose of the current study was to investigate whether prophylactic cranial irradiation (PCl) reduces the incidence of symptomatic brain metastases in patients with stage III non-small-cell lung cancer (NSCLC) treated with curative intention.

\section{Patients and Methods}

Patients with stage III NSCLC—staged with a contrast-enhanced brain computed tomography or magnetic resonance imaging-were randomly assigned to either observation or $\mathrm{PCl}$ after concurrent/sequential chemoradiotherapy with or without surgery. The primary end point-development of symptomatic brain metastases at 24 months-was defined as one or a combination of key symptoms that suggest brain metastases-signs of increased intracranial pressure, headache, nausea and vomiting, cognitive or affective disturbances, seizures, and focal neurologic symptoms-and magnetic resonance imaging or computed tomography demonstrating the existence of brain metastasis. Adverse effects, survival, quality of life, quality-adjusted survival, and health care costs were secondary end points.

\section{Results}

Between 2009 and 2015, 175 patients were randomly assigned: 87 received $\mathrm{PCl}$ and 88 underwent observation only. Median follow-up was 48.5 months ( $95 \% \mathrm{Cl}, 39$ to 54 months). Six (7.0\%) of 86 patients in the $\mathrm{PCl}$ group and $24(27.2 \%)$ of 88 patients in the control group had symptomatic brain metastases $(P=.001)$. PCl significantly increased the time to develop symptomatic brain metastases (hazard ratio, 0.23; [95\% Cl, 0.09 to 0.56]; $P=.0012$ ). Median time to develop brain metastases was not reached in either arm. Overall survival was not significantly different between both arms. Grade 1 and 2 memory impairment (26 of $86 v$ seven of 88 patients) and cognitive disturbance (16 of $86 v$ three of 88 patients) were significantly increased in the $\mathrm{PCl}$ arm. Quality of life was only decreased 3 months post- $\mathrm{PCl}$ and was similar to the observation arm thereafter.

\section{Conclusion}

$\mathrm{PCl}$ significantly decreased the proportion of patients who developed symptomatic brain metastases with an increase of low-grade toxicity.

\section{J Clin Oncol 36:2366-2377. (c) 2018 by American Society of Clinical Oncology}

\section{INTRODUCTION}

Incidence of brain metastases in patients with localized non-small-cell lung cancer (NSCLC) varies approximately from $5 \%$ to $40 \%$. $^{1,2}$ In stage III NSCLC, the cumulative incidence of brain metastases, at present, is consistently approximately $30 \%$ at 2 years, even after adequate brain imaging at staging. ${ }^{2}$
In localized small-cell lung cancer, prophylactic cranial irradiation (PCI) has been shown to decrease the incidence of brain metastases by approximately $50 \%$, with improved long-term overall survival (OS) as a result. ${ }^{3,4}$

PCI has also been the subject of randomized controlled trials in localized NSCLC, which have consistently demonstrated that PCI reduces the incidence of brain metastases on imaging more than $50 \%{ }^{5-11}$; however, PCI may lead to neurocognitive 


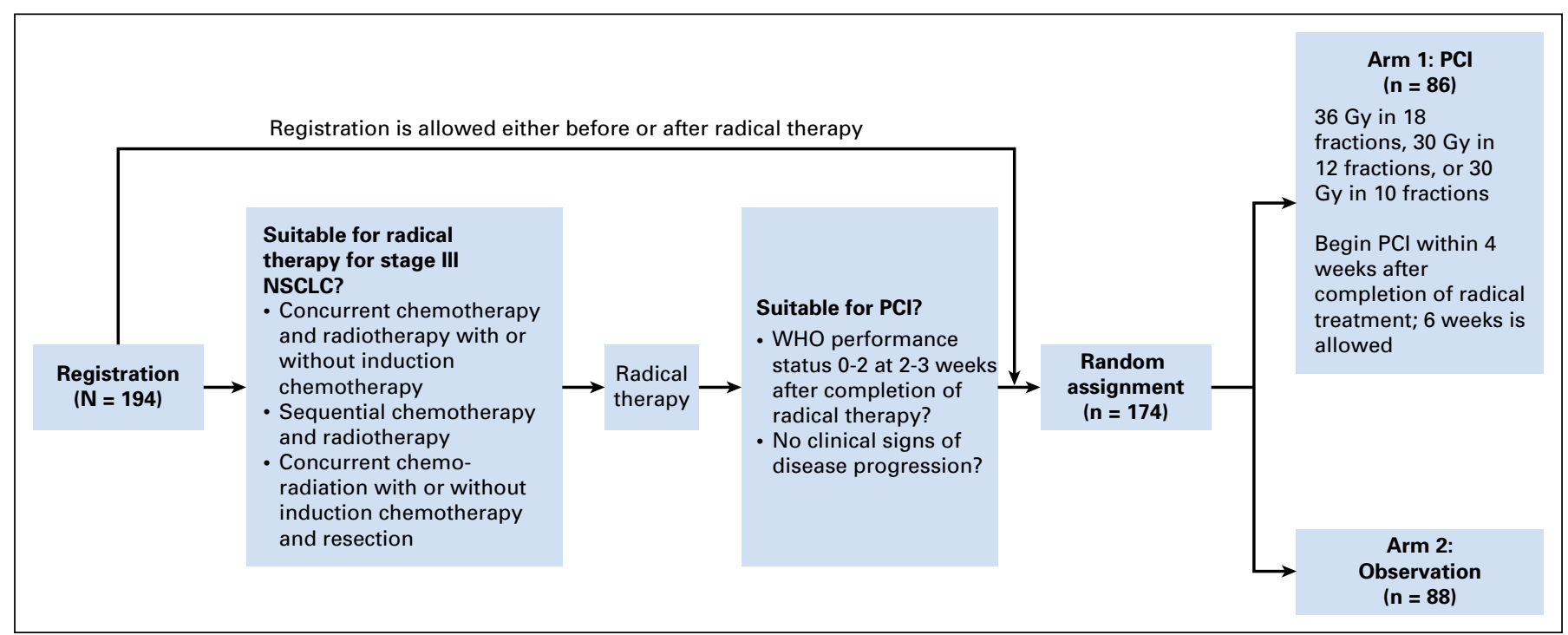

Fig 1. CONSORT diagram. NSCLC, non-small-cell lung cancer; $\mathrm{PCl}$, prophylactic cranial irradiation.

decline in a significant proportion of patients, ${ }^{12}$ and in none of the PCI studies was survival improved.

As symptomatic brain metastases are devastating for patients, impairing quality of life (QoL), ${ }^{13}$ we have performed a randomized study to investigate whether PCI reduces the proportion of patients with symptomatic brain metastases.

\section{PATIENTS AND METHODS}

\section{Patients}

Patients with stage III NSCLC—-staging included contrast-enhanced brain computed tomography (CT) or magnetic resonance imaging (MRI) and a whole-body ${ }^{18} \mathrm{~F}$-labeled fluorodeoxyglucose positron emission tomography-CT scan (IASLC 7th edition staging) - were randomly assigned to either observation or PCI after concurrent/sequential chemoradiotherapy with or without surgery if they did not show tumor progression (Fig 1). PCI should start, at maximum, 6 weeks after the last chemotherapy administration. PCI dose was left to the choice of the participating hospitals-36 Gy in 18 fractions, 30 Gy in 12 fractions, or $30 \mathrm{~Gy}$ in 10 fractions. Patients were randomly assigned after consultation by a medical specialists to assess symptoms, toxicity according to Common Terminology Criteria for Adverse Events (version 3.0) and WHO performance status, European Organisation for Research and Treatment of Cancer Quality of Life Questionnaire C30, and EuroQol 5D measurement. After random assignment, follow-up was performed with similar assessments at 4, 3, 6, 12, and 24 weeks and 36 months or earlier when symptoms of brain metastasis occurred. Key symptoms were defined as one or a combination of signs of increased intracranial pressure, headache, nausea and vomiting, cognitive or affective disturbances, seizures, and/or focal neurologic symptoms. MRI or CT was then performed to prove the existence of brain metastasis. Adverse effects, OS, quality of life (Quality of Life Questionnaire C30 + BN20 and EuroQol 5D), quality-adjusted survival, and health care costs were secondary end points.

\section{Statistical Considerations}

The primary end point was the proportion of patients who developed symptomatic brain metastases within 24 months since the time of random assignment. Symptomatic brain metastases were defined by the development of new key symptoms.
The primary end point - the relationship between PCI and the incidence of symptomatic brain metastases-was assessed with Fisher exact test. $P$ values $<.05$ were considered statistically significant.

The time to develop brain metastases-defined as time since random assignment to the first occurrence of symptomatic brain metastases-was estimated using the Fine-Gray model, using death of any cause as competing risk. Brain metastasis-free survival (time since random assignment to first occurrence of brain metastases or death), progression-free survival (time since random assignment to first occurrence of disease progression, including but not limited to brain metastases, or death), and OS (time since random assignment to death of any cause) were estimated using the Kaplan-Meier method with right censoring at the time of last follow-up in case the event of interest had not occurred. Differences in these outcomes between the groups were calculated using the log-rank test and Cox proportional hazards regression models.

To evaluate the differences in adverse effects between arms, we used the Holms-Bonferroni correction to avoid false-positive significant associations.

\begin{tabular}{|c|c|c|c|}
\hline \multirow[b]{2}{*}{ Characteristic } & \multicolumn{2}{|c|}{ Treatment Arm } & \multirow[b]{2}{*}{$\begin{array}{c}\text { Total } \\
(\mathrm{N}=174)\end{array}$} \\
\hline & $\begin{array}{c}\mathrm{PCl} \\
(\mathrm{n}=86)\end{array}$ & $\begin{array}{l}\text { Observation } \\
(n=88)\end{array}$ & \\
\hline Gender (male/female) & $58 / 28$ & $56 / 32$ & $114 / 60$ \\
\hline \multicolumn{4}{|l|}{ Histology, No. (\%) } \\
\hline Adenocarcinoma & 31 & 41 & $72(41)$ \\
\hline Squamous-cell carcinoma & 33 & 29 & $62(36)$ \\
\hline Large cell & 19 & 13 & 32 (18) \\
\hline NSCLC NOS & 3 & 5 & $8(5)$ \\
\hline \multicolumn{4}{|c|}{ WHO performance status, No. (\%) } \\
\hline 0 & 32 & 34 & $66(38)$ \\
\hline 1 & 50 & 49 & $99(57)$ \\
\hline 2 & 4 & 5 & $9(5)$ \\
\hline \multicolumn{4}{|l|}{ Stage, No. (\%) } \\
\hline$\| \mathrm{A} A$ & 41 & 52 & $93(53)$ \\
\hline IIIB & 44 & 36 & $80(46)$ \\
\hline Unknown & 1 & 0 & $1(1)$ \\
\hline Median follow-up, months & 48.5 & 48.8 & 48.5 \\
\hline $95 \% \mathrm{Cl}$, months & 39 to 54 & 38 to 60 & 39 to 54 \\
\hline
\end{tabular}




\begin{tabular}{|lc|}
\hline \multicolumn{2}{|c|}{ Table 2. PCl Dose } \\
\hline PCl Dose and Fraction & No. of Patients \\
\hline 12 fractions of $30 \mathrm{~Gy}$ & 38 \\
10 fractions of $30 \mathrm{~Gy}$ & 34 \\
10 fractions of $25 \mathrm{~Gy}$ & 3 \\
18 fractions of $36 \mathrm{~Gy}$ & 1 \\
12 fractions of $20 \mathrm{~Gy}$ & 1 \\
1 fraction of $3 \mathrm{~Gy}$ & 1 \\
0 Gy (no PCl) & 8 \\
\hline NOTE. Data are presented as No. unless otherwise noted. & \\
Abbreviation: PCl, prophylactic cranial irradiation. & \\
\hline
\end{tabular}

Random assignment was stratified for histology, WHO performance status, prior surgery and institute. Subgroup analysis within levels of the stratification factors, with the exception of institute, were planned for in the protocol.

\section{Sample Size and Power}

Approximately 1,500 patients with stage III NSCLC are treated with curative intent each year in the Netherlands. Six hundred of these 1,500 patients were expected to fulfill the inclusion criteria, and approximately $35 \%$ of 600 patients -210 patients per year-were assumed to be willing to participate in this trial. As not all hospitals in the Netherlands participated in this trial, we expected that approximately 150 patients per year would be registered in the study in our country. Of these 150 , it was estimated that $30 \%$ would not reach random assignment, leaving 105 patients randomly assigned per year.

Among this group of patients with stage III NSCLC who were treated with chemoradiation, we expected to find in the control group (no PCI) that $30 \%$ of patients would have symptomatic brain metastases after 24 months.

A total of 300 patients-approximately 450 would need to be registered-would be randomly assigned in the study, 150 in each arm. When performing statistical analysis at approximately 24 months after the end of patient accrual, a total of 100 patients would have developed symptomatic brain metastases in both arms together. The study would then have $90 \%$ power-a two-sided significance level of .05-to detect a decrease to $17 \%$ in the proportion of patients who developed symptomatic brain metastases at 24 months using a log-rank test-that is, treating development of symptomatic brain metastases as a time-to-event outcome.

The estimated inclusion period would therefore be approximately 36 months. To obtain reliable 2-year data, another 2 years of follow-up would be necessary. Patients would be observed to at least 36 months after random assignment. Assuming an exponential distribution in the times to occurrence of symptomatic brain metastases, the above proportions at 2 years correspond to a hazard ratio (HR) of 0.52 . In addition, the number of patients randomly assigned in the study would allow in excess of $80 \%$ to detect a more moderate HR of 0.55 between the time to develop neurologic symptoms - confirmed or not—in both treatment arms (two-sided test, .05).

However, accrual to the study was slower than expected because, after the end of chemotherapy and radiotherapy, many patients expected that the burden of additional PCI would be too high. In March 2013, it was therefore decided that the envisioned total amount of patients-450 patients registered and 300 randomly assigned - could not be reached. We thus performed a new power calculation. We now estimated that only 170 patients would be accrued after 5 years. After an additional 2 years of follow-up, assuming exponential event rates, we estimated that 75 events would have occurred. With 75 events, a two-sided log-rank test would still have $80 \%$ power to detect the above HR of 0.52 with an $\alpha$ of .05; however, the power to detect the more moderate HR of 0.55 would have dropped to $73 \%$.

\section{Ethical and Regulatory Considerations}

The study was conducted in agreement with the Declaration of Helsinki-Tokyo, Venice, Hong Kong, Somerset West, and Edinburgh amendments - and the laws and regulations of the Netherlands. The study was approved by the medical ethical committees of all participating hospitals in accordance with Dutch laws and regulations. Written informed consent was obtained from all patients.

The study was registered in The Netherlands Trial Registry, number NTR1601.

\section{RESULTS}

\section{Patients}

Between 2009 and 2015, a total of 195 patients were registered; 175 were randomly assigned, 87 received PCI, and 88 patients underwent observation. Patient characteristics are listed in Table 1.

The majority of patients in both arms received definitive concurrent chemotherapy and radiotherapy-68 (77\%) of 88 patients in the observation arm and $72(84 \%)$ of 86 patients in the PCI arm. Sequential chemoradiotherapy was provided in $12(14 \%)$ of 88 patients in the observation arm and in six (7\%) of 86 patients in the PCI group. Concurrent chemoradiotherapy followed by surgery was performed in four of 88 patients in the observation group and in four of 86 patients in the PCI arm.

Eighty percent (70 of 88 ) of patients in the observation arm and $79 \%$ (68 of 86 ) in the PCI arm received a combination platinum-based therapy. Single-agent platinum was administered to $14(16 \%)$ of 88 and $15(17 \%)$ of 86 patients in the observation and PCI arms, respectively.

Of the 86 patients in the PCI arm, 78 (91\%) completed the treatment according to the protocol. Seven patients did not begin with PCI and one patient stopped after one fraction because of migraine, nausea, and vomiting.

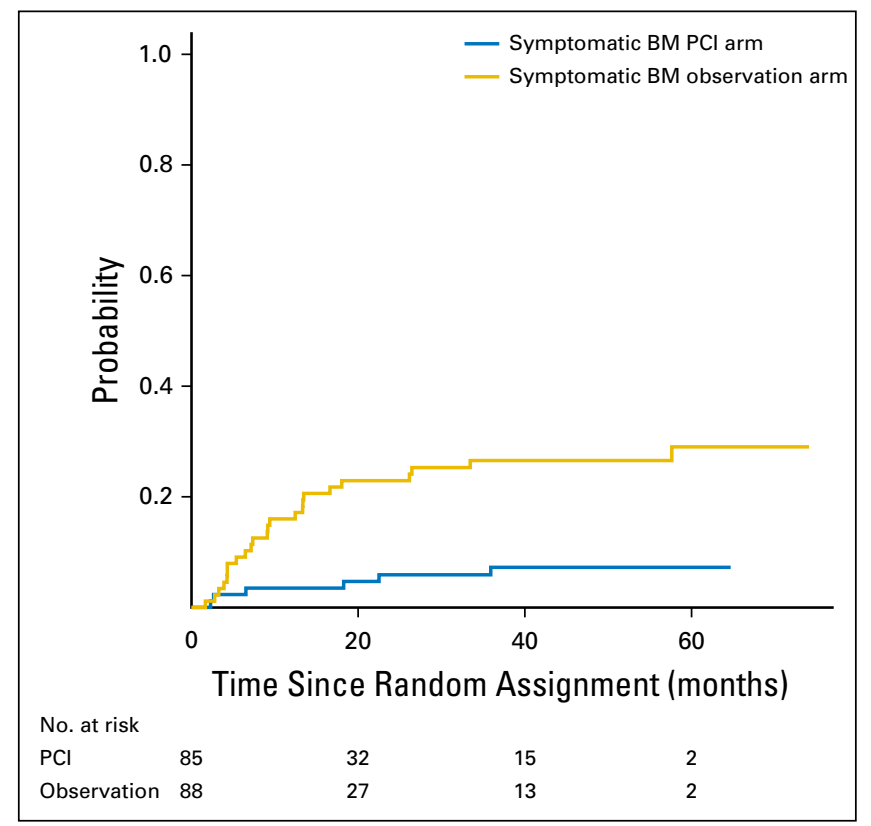

Fig 2. Cumulative incidence of symptomatic brain metastases (BM) by arm (solid lines) with death as a competing risk. Prophylactic cranial irradiation (PCl) increased the time to symptomatic BM (hazard ratio, $0.23[95 \% \mathrm{Cl}, 0.09$ to 0.56 ]; $P=.0012) . \mathrm{PCl}$, prophylactic cranial irradiation. 


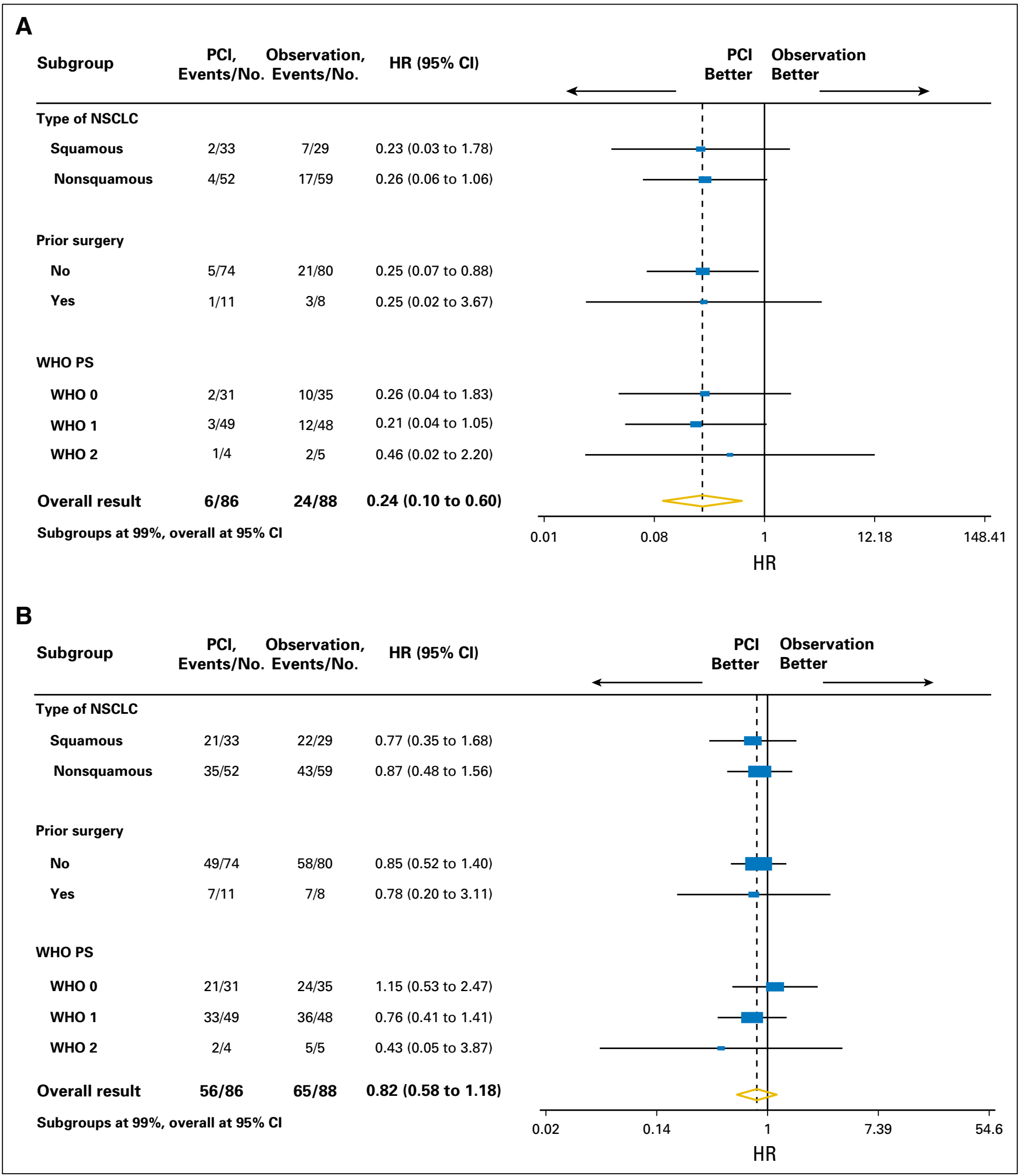

Fig 3. (A and B) Forrest plots of planned subgroup analyses: (A) time to develop symptomatic brain metastases and (B) brain metastasis-free survival. HR, hazard ratio; NSCLC, non-small-cell lung cancer; PCl, prophylactic cranial irradiation; PS, performance status.

Most patients received either 30 Gy in 12 fractions or 30 Gy in 10 fractions (Table 2). Median follow-up was 48.5 months (95\% CI, 39 to 54 months).

\section{Symptomatic Brain Metastases}

Six $(7.0 \%)$ of 87 patients in the PCI arm and $24(27.2 \%)$ of 88 patients in the control group $(P<.001)$ had developed 


\begin{tabular}{|c|c|c|c|c|c|c|}
\hline \multirow[b]{2}{*}{ Adverse Event } & \multicolumn{3}{|c|}{ All Grades } & \multicolumn{3}{|c|}{ Grade 3-5 } \\
\hline & $\mathrm{PCl}(\mathrm{n}=86)$ & Observation $(n=88)$ & All $(N=174)$ & $\mathrm{PCl}(n=86)$ & Observation $(n=88)$ & All $(N=174)$ \\
\hline Ataxia & 2 & 0 & 2 & 1 & 0 & 1 \\
\hline Blurred vision & 1 & 2 & 3 & 0 & 0 & 0 \\
\hline Carpal tunnel syndrome & 0 & 1 & 1 & 0 & 0 & 0 \\
\hline Cauda syndrome & 0 & 1 & 1 & 0 & 0 & 0 \\
\hline Cerebrovascular accident & 2 & 0 & 2 & 1 & 0 & 1 \\
\hline Cognitive disturbance & 18 & 3 & 21 & 2 & 0 & 2 \\
\hline Concentration impairment & 3 & 1 & 4 & 0 & 0 & 0 \\
\hline Confusion & 4 & 2 & 6 & 1 & 1 & 2 \\
\hline Depressed level of consciousness & 0 & 1 & 1 & 0 & 0 & 0 \\
\hline Dizziness & 22 & 13 & 35 & 1 & 0 & 1 \\
\hline Failure arm & 0 & 1 & 1 & 0 & 0 & 0 \\
\hline Fall & 1 & 0 & 1 & 0 & 0 & 0 \\
\hline Hearing impaired & 1 & 0 & 1 & 0 & 0 & 0 \\
\hline Insomnia & 0 & 1 & 1 & 0 & 0 & 0 \\
\hline Ischemia cerebrovascular & 2 & 0 & 2 & 1 & 0 & 1 \\
\hline Itching ears & 1 & 0 & 1 & 0 & 0 & 0 \\
\hline Leucoencephalopathy & 1 & 0 & 1 & 1 & 0 & 1 \\
\hline Memory impairment & 26 & 7 & 33 & 0 & 0 & 0 \\
\hline Mental status & 2 & 0 & 2 & 0 & 0 & 0 \\
\hline Mood alteration & 2 & 0 & 2 & 0 & 0 & 0 \\
\hline Neuropathy & 13 & 14 & 27 & 2 & 3 & 5 \\
\hline Paresis & 1 & 0 & 1 & 0 & 0 & 0 \\
\hline Parkinson disease & 1 & 0 & 1 & 0 & 0 & 0 \\
\hline Personality change & 3 & 0 & 3 & 0 & 0 & 0 \\
\hline Personality change & 1 & 0 & 1 & 0 & 0 & 0 \\
\hline Restlessness & 0 & 1 & 1 & 0 & 0 & 0 \\
\hline SAB hemisphere left & 1 & 0 & 1 & 1 & 0 & 1 \\
\hline Seizure & 4 & 1 & 5 & 2 & 0 & 2 \\
\hline Somnolence & 9 & 4 & 13 & 1 & I & 2 \\
\hline Speech impairment & 8 & 2 & 10 & 2 & 0 & 2 \\
\hline
\end{tabular}

symptomatic brain metastases at 2 years after therapy. Odds ratio was 4.96 (95\% CI, 1.83 to 15.7$)$.

PCI thus decreased the cumulative incidence of symptomatic brain metastases and significantly increased the time to develop symptomatic brain metastases (HR, 0.23 [95\% CI, 0.09 to 0.56]; $P=.0012$; Fig 2). Median time to develop symptomatic brain metastases was not reached in either arm, mostly as a result of the competing risk of death.

In four patients-three in the control arm and one in the PCI arm-brain metastases were found by imaging without neurologic symptoms being reported.

\section{Planned Subgroup Analyses}

The influence of the stratification factors, histologic subtype of NSCLC, WHO performance status, and prior surgery (used in the random assignment), on the effectiveness of PCI to prolong the time to develop symptomatic brain metastases and brain metastasisfree survival were assessed as shown in the forest plots in Figures 3A and $3 \mathrm{~B}$, respectively.

For none of the factors was the effect of PCI different between factor levels - that is, none of the tests for interaction between arm and stratification factor was significant.

\section{Neurologic Adverse Events}

Neurologic adverse events (AE) were scored by the physician. Grade 1 and 2 AEs occurred numerically more frequently in the
PCI group (Table 3). Only grade 1 and 2 memory impairment (26 of $86 v$ seven of 88 patients) and cognitive disturbance (16 of $86 v$ three of 88 patients) were significantly increased in the PCI arm. The number of grade 3 to 5 toxicities was low in both arms.

\section{Non-Neurologic AEs}

Non-neurologic AEs were scored by the physician. Alopecia, fatigue, and headache were significantly more frequent in the PCI arm, occurring in 36 of 86 patients versus five of 88 patients, 55 of 86 patients versus 30 of 88 patients, and 33 of 86 patients versus 12 of 88 patients, respectively (Table 4). Severe toxicity was rare in both study arms.

\section{Patient-Reported AEs}

Patients scored dizziness, headache, hypersomnia, memory impairment, and vomiting. AEs were numerically higher in the PCI arm than in the observation arm, but only headache occurred significantly more frequent in the PCI arm (55 of 87 patients $v 36$ of 88 patients, respectively; Table 5). Grade $\geq 3$ AEs were rare in both study arms.

\section{Differences Between Patient- and Physician-Reported Incidence of AEs}

As depicted in Table 6, patient and physician scoring was not always concordant. With the exception of vomiting, 
Table 4. Non-Neurologic Adverse Events (scored by the physician)

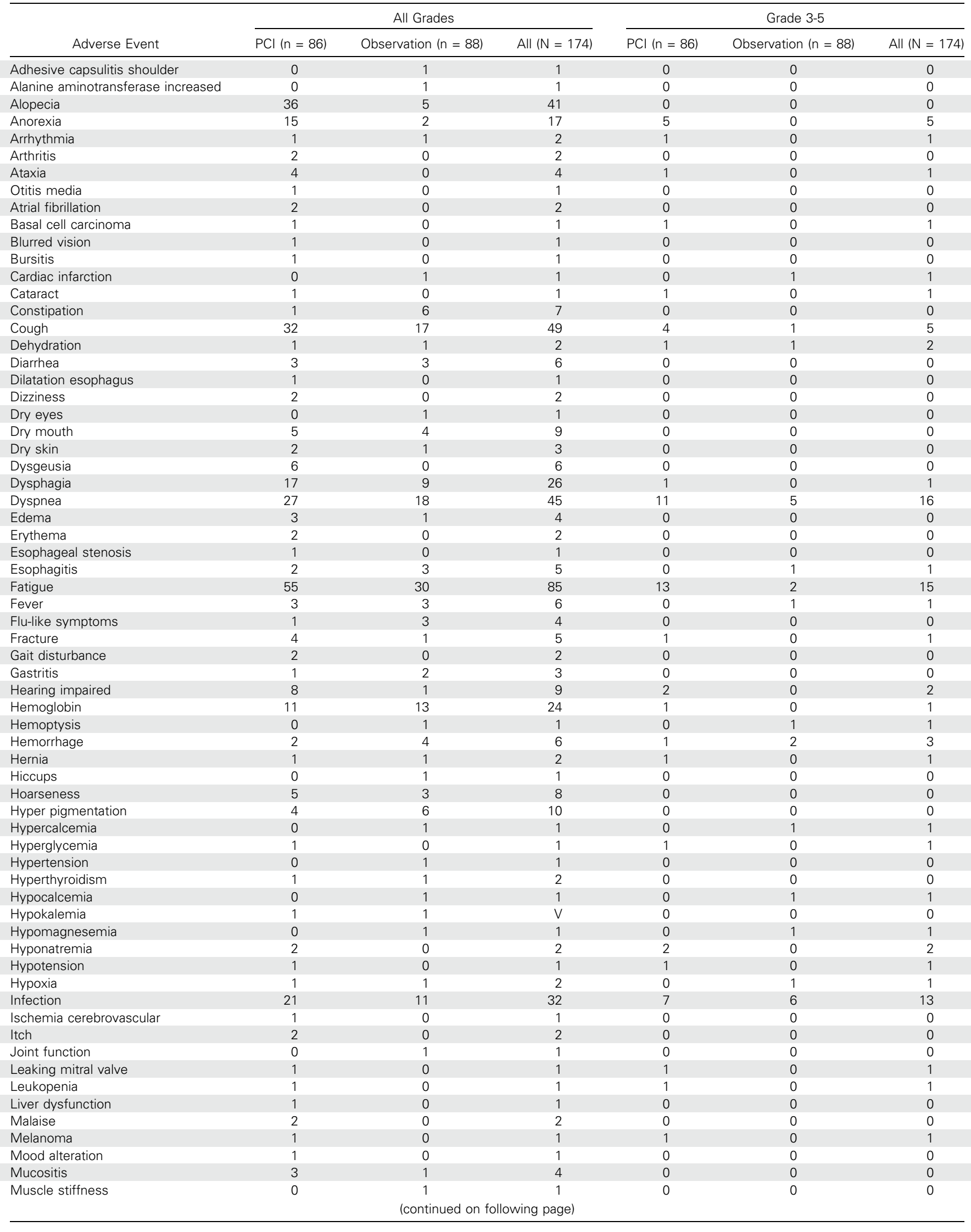




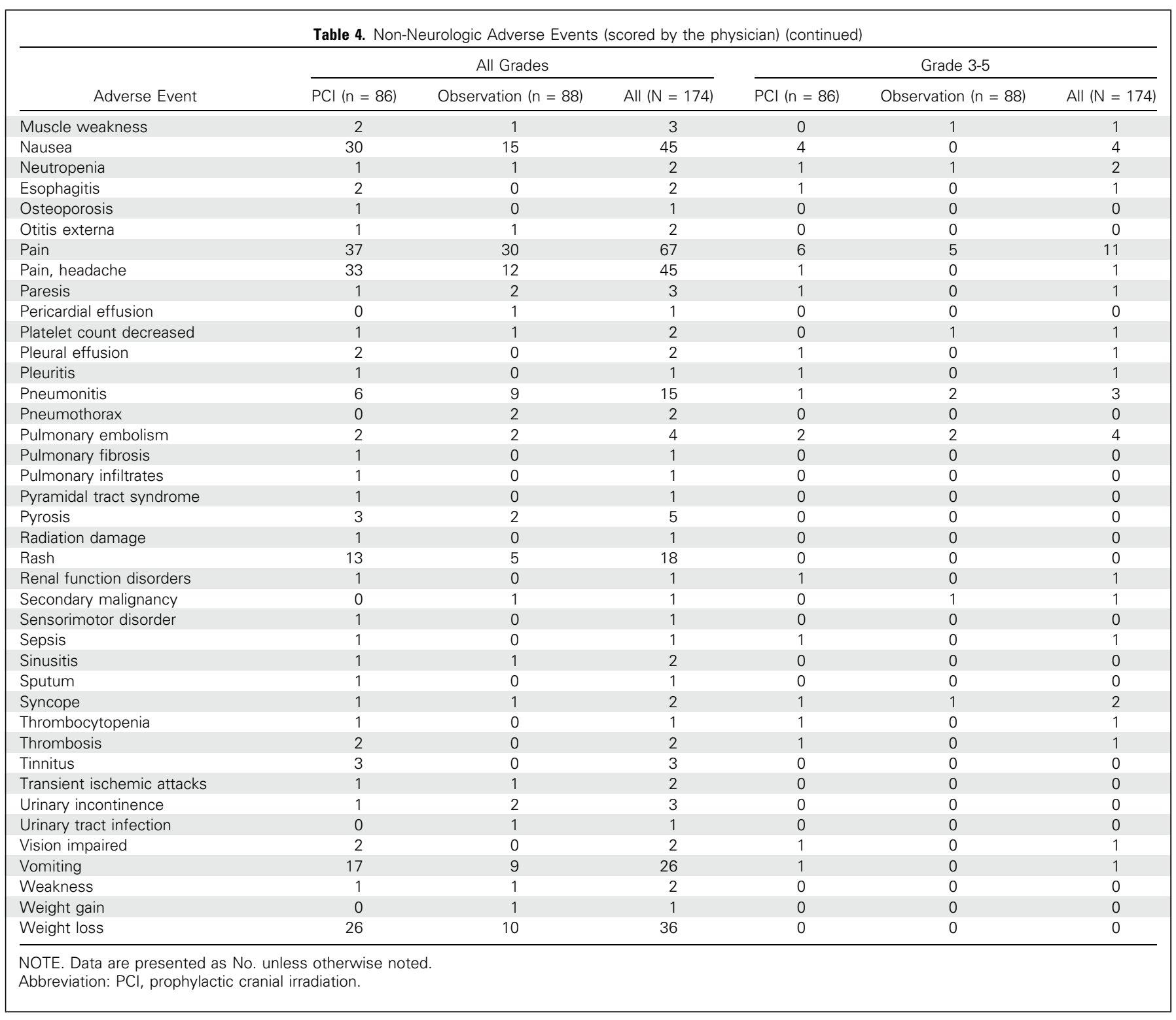

all AEs were under-reported by physicians. Fatigue and memory impairment were more reported by patients compared with physicians in the observation arm versus the PCI arm.

\section{Evolution of AEs Over Time}

There were striking differences in the time course of AEs, scored by physicians, between neurologic AEs (Fig 4) and nonneurologic AEs (Fig 5).

\begin{tabular}{|c|c|c|c|c|c|c|}
\hline \multirow[b]{2}{*}{ Adverse Event } & \multicolumn{3}{|c|}{ All Grades } & \multicolumn{3}{|c|}{ Grade 3 and 4} \\
\hline & $\mathrm{PCl}(\mathrm{n}=87)$ & Observation ( $\mathrm{n}=88$ ) & All $(N=175)$ & $\mathrm{PCl}(\mathrm{n}=87)$ & Observation $(\mathrm{n}=88$ ) & All $(N=175)$ \\
\hline Dizziness & 50 & 36 & 86 & 1 & 0 & 1 \\
\hline Headache & 55 & 36 & 91 & 4 & 2 & 6 \\
\hline Hypersomnia & 69 & 70 & 139 & 3 & 5 & 8 \\
\hline Memory impairment & 50 & 47 & 97 & 2 & 1 & 3 \\
\hline Vomiting & 16 & 6 & 22 & 0 & 0 & 0 \\
\hline
\end{tabular}


Table 6. Differences Between Patient- and Physician-Reported Adverse Events

\begin{tabular}{|c|c|c|c|}
\hline Adverse Event & $\mathrm{PCl}$ & Observation & Total \\
\hline \multicolumn{4}{|l|}{ Dizziness } \\
\hline Reported by patient, not by physician & 31 & 28 & 59 \\
\hline Reported by physician, not by patient & 4 & 5 & 9 \\
\hline Reported by both, same (highest) grade & 12 & 5 & 17 \\
\hline Reported by both, patient reports higher grade & 6 & 1 & 7 \\
\hline Reported by both, physician reports higher grade & 1 & 2 & 3 \\
\hline Sum & 54 & 41 & 95 \\
\hline \multicolumn{4}{|l|}{ Headache } \\
\hline Reported by patient, not by physician & 28 & 29 & 57 \\
\hline Reported by physician, not by patient & 6 & 5 & 11 \\
\hline Reported by both, same (highest) grade & 19 & 4 & 23 \\
\hline Reported by both, patient reports higher grade & 6 & 1 & 7 \\
\hline Reported by both, physician reports higher grade & 2 & 2 & 4 \\
\hline Sum & 61 & 41 & 102 \\
\hline \multicolumn{4}{|l|}{ Hypersomnia/fatigue } \\
\hline Reported by patient, not by physician & 23 & 44 & 67 \\
\hline Reported by physician, not by patient & 9 & 4 & 13 \\
\hline Reported by both, same (highest) grade & 16 & 15 & 31 \\
\hline Reported by both, patient reports higher grade & 13 & 7 & 20 \\
\hline Reported by both, physician reports higher grade & 17 & 4 & 21 \\
\hline Sum & 78 & 74 & 152 \\
\hline \multicolumn{4}{|l|}{ Memory impairment } \\
\hline Reported by patient, not by physician & 27 & 40 & 67 \\
\hline Reported by physician, not by patient & 3 & 0 & 3 \\
\hline Reported by both, same (highest) grade & 15 & 6 & 21 \\
\hline Reported by both, patient reports higher grade & 2 & 0 & 2 \\
\hline Reported by both, physician reports higher grade & 6 & 1 & 7 \\
\hline Sum & 53 & 47 & 100 \\
\hline \multicolumn{4}{|l|}{ Vomiting } \\
\hline Reported by patient, not by physician & 9 & 4 & 13 \\
\hline Reported by physician, not by patient & 10 & 7 & 17 \\
\hline Reported by both, same (highest) grade & 3 & 1 & 4 \\
\hline Reported by both, patient reports higher grade & 2 & 0 & 2 \\
\hline Reported by both, physician reports higher grade & 2 & 1 & 3 \\
\hline Sum & 26 & 13 & 39 \\
\hline
\end{tabular}

NOTE. Data are presented as No. unless otherwise noted.

Abbreviation: $\mathrm{PCl}$, prophylactic cranial irradiation.

Although both neurologic and non-neurologic AEs were more frequent in PCI-treated patients than in the observation arm, neurologic AEs tended to increase over time after PCI, whereas non-neurologic AEs were the highest during PCI and decreased continuously over time.

\section{OS, Symptomatic Brain Metastasis-Free Survival, and Progression-Free Survival}

After a median follow-up time of 51.3 months (95\% CI, 47.5 to 60.2 months), there was no difference in OS between the arms (HR, 0.9 [95\% CI, 0.62 to 1.29; Fig 6A]). Median OS was slightly longer in the PCI arm than in the control arm (24.2 months [95\% CI, 20.3 to 38.7 months] $v 21.9$ months [95\% CI, 18.1 to 33.7 months], respectively), but this difference was not statistically significantly different $(P=.56)$.

PCI significantly increased the time to develop brain metastases in all patients treated, but this was not the case for brain metastasis-free survival (HR, 0.81 [95\% CI, 0.57 to 1.16]).

Median progression-free survival was slightly longer in the PCI arm than in the control arm (12.3 months [95\% CI, 9.4 to 21.2 months] $v 11.5$ months [95\% CI, 7.8 to 15.8 months], respectively), but this difference was not statistically significantly different $(P=.17$; Fig $6 \mathrm{~B})$. HR was 0.79 (95\% CI, 0.56 to 1.11$)$.

\section{QoL}

QoL was similar between both arms at baseline. At 3 months after PCI, QoL was worse in the PCI arm, particularly in physical functioning (median scores: PCI, 73; observation, 87; $P=.0017$ ). At 6, 12, and 18 months, QoL was similar between both arms, but long term-24, 36, and 48 months - there was a slight, nonsignificant advantage in QoL in the observation arm.

\section{DISCUSSION}

Brain metastases are common in locally advanced NSCLC. ${ }^{1,13}$ Patients with brain metastases have impaired QoL and decreased neurocognitive functioning that may improve with successful therapy of brain metastases. ${ }^{14}$ Overall prognosis for these patients remains poor. ${ }^{15}$

It is therefore logical that PCI, which decreases the incidence of brain metastases in localized small-cell lung cancer and can lead to improved long-term survival, ${ }^{3}$ has also been investigated in the treatment of localized NSCLC. ${ }^{5-11}$ All these phase III studies have consistently shown a decrease of the incidence of brain metastases detected with imaging, but none has shown increased OS.

We therefore started a randomized phase III study to investigate the influence of PCI on symptomatic brain metastases. Incidence of 


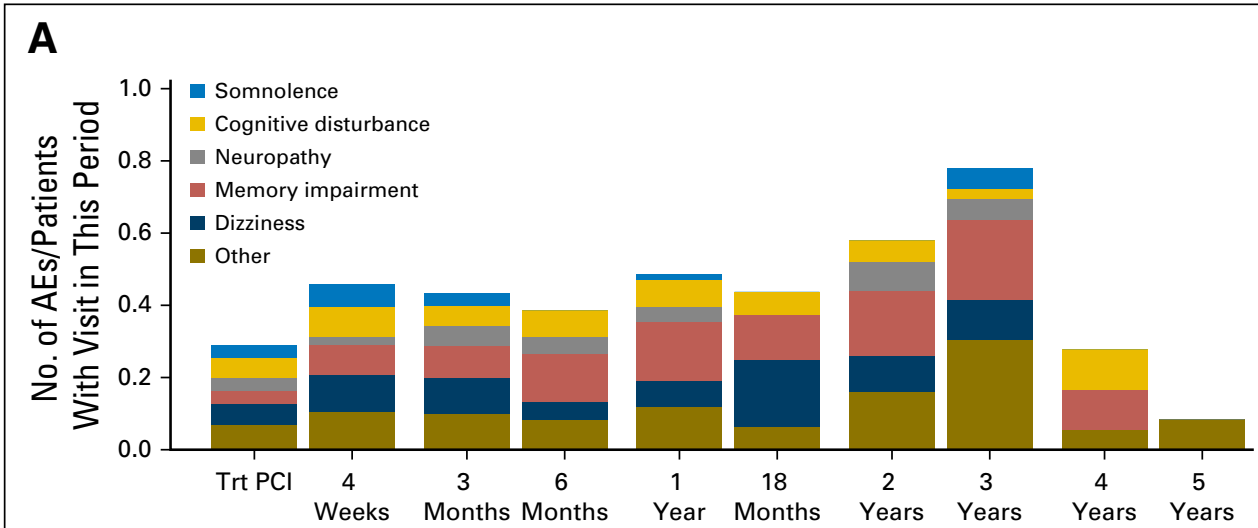

B

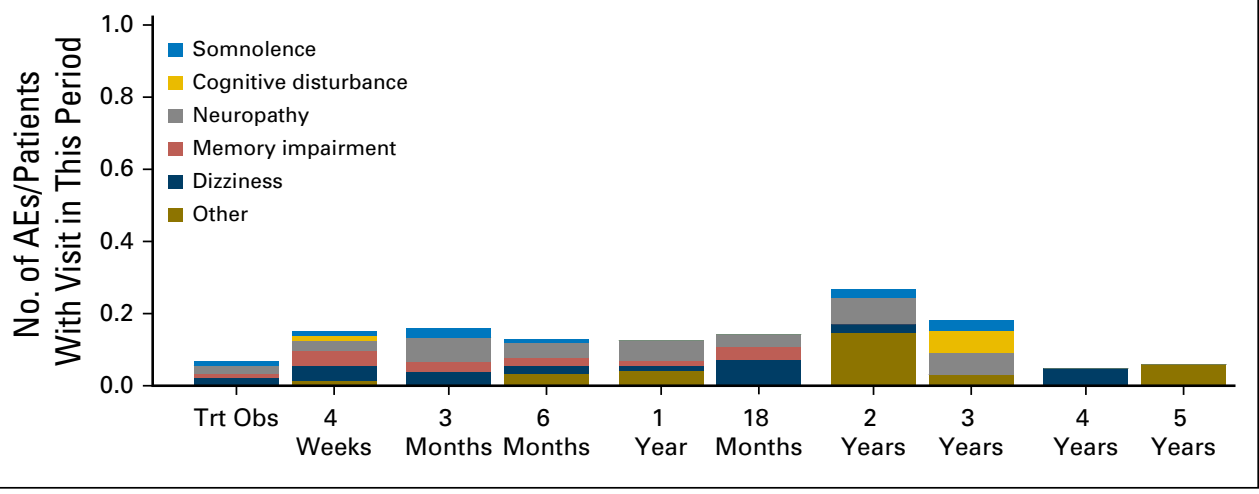

Fig 4. Number of neurologic adverse events (AEs) over time. (A) Prophylactic cranial irradiation $(\mathrm{PCl})$ arm only. (B) Observation arm only. Trt, before initiation. symptomatic brain metastases at 2 years was chosen as this was deemed to be an end point that is important for the patient.

We have indeed shown that PCI significantly reduced the incidence of symptomatic brain metastases from $27.2 \%$ in the observation arm to $7.0 \%$ in the PCI arm $(P<.001)$. The number needed to treat is therefore 4.95 ; therefore, by treating approximately five patients with PCI we can prevent one case of symptomatic brain metastasis.

Patients who received PCI had more neurologic AEs, but most of them were low grade (grade 1 and 2). Only grade 1 and 2 memory impairment $(30 \% \vee 8 \%$, respectively) and cognitive disturbance (19\% $v 3 \%$, respectively) were significantly increased in the PCI arm compared with the observation arm.

The non-neurological AEs, alopecia, fatigue, and headache. were significantly more frequent in the PCI arm, occurring in $42 \%$ versus $6 \%, 64 \%$ versus $34 \%$, and $38 \%$ versus $14 \%$ of patients. Severe toxicity was rare in both study arms.

When assessing patient-reported AEs, only low-grade headache occurred significantly more frequently in the PCI arm (63\% v $41 \%$, respectively).

With the exception of vomiting, all AEs were under-reported by physicians compared with patients. Fatigue and memory impairment were much more under-reported by physicians in the observation arm than in the PCI arm. Considering the results of patient reports, memory impairment would not seem different between the two study arms, for it was reported by $57 \%$ and $54 \%$ of patients in the PCI arm and observation arm, respectively. According to physicians, the same AE would only be observed in $8 \%$ of patients in the observation arm and in $30 \%$ of patients in the PCI arm. This may be a result of a priori bias of physicians and underscores the need for assessment of patient-reported outcomes and objective tests.

The timelines of neurologic AEs are different from nonneurologic AEs: the former increased over time, whereas the latter were the highest during PCI and decreased thereafter.

Three months after PCI, QoL was worse in the PCI arm, but thereafter returned to the same level as that of the observation arm. After $\geq 2$ years, QoL was slightly better in the observation arm, but this did not reach statistical significance up to 48 months after PCI. More detailed information for QoL items is needed to include this in the evaluation of the beneficial and deleterious effects of PCI.

OS and progression-free survival were similar in both arms; this is the key element in the controversy that surrounds PCI. PCI is clearly efficacious in reducing the incidence of brain metastases in all randomized studies. In a meta-analysis on the basis of on published data from phase III trials, the relative risk to decrease brain metastases was 0.33 (95\% CI, 0.24 to 0.45; summarized in Fig 7); however, at present, no single study has demonstrated an effect on OS. In the current study, at 2 years, approximately $67 \%$ of patients in the PCI arm and $72 \%$ in the observation arm showed a recurrence. As the absolute reduction in brain metastases was $20 \%$, it is clear that the majority of patients developed extracranial recurrences, thus lowering the potential effect of PCI on OS.

The absence of an effect-either beneficial or deleterious - on OS may be explained by the large extent of extracranial metastases that develop, a lack of statistical power in the current studies, the too-short follow-up time in some trials, or only a marginal effect. Another explanation for the absence of improvement in OS may be the effect of subsequent treatment of (a)symptomatic brain metastases in the observation arm-for instance, by radiosurgery. The 


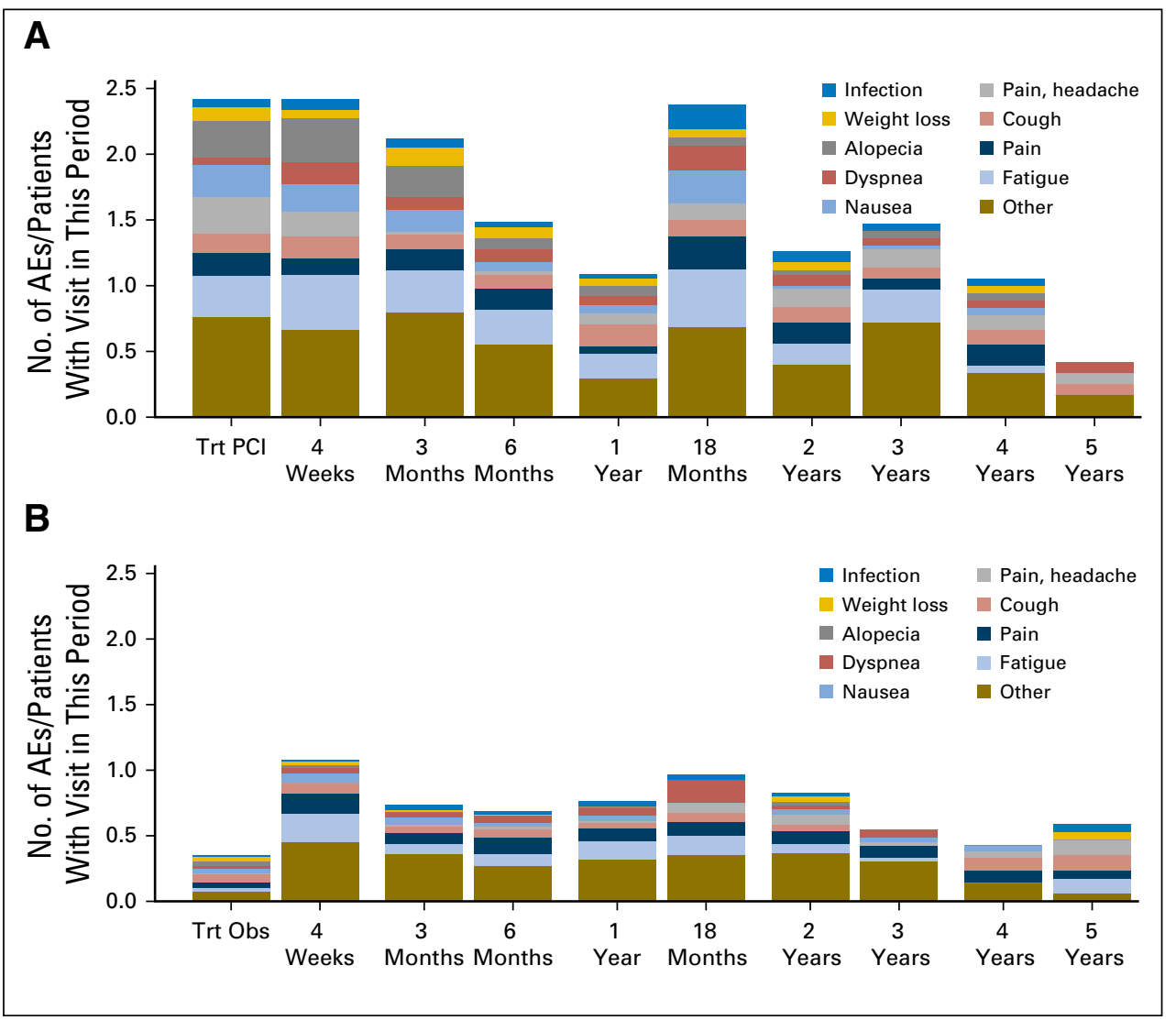

Fig 5. Number of non-neurologic adverse events (AEs) over time. (A) Prophylactic cranial irradiation (PCI) arm only. (B) Observation arm only. Trt, before initiation.

neurocognitive AEs of PCI may be reduced by, for example, sparing of the hippocampus, pharmacologic interventions, or MRI followup with radiosurgery for recurrences ${ }^{12}$; however, these strategies, at present, are experimental.
The type of chemotherapy that is used presently does not influence the incidence of brain metastases ${ }^{16}$; however, the first results with the programmed death-ligand 1 inhibitor, durvalumab, when administered after concurrent chemotherapy and

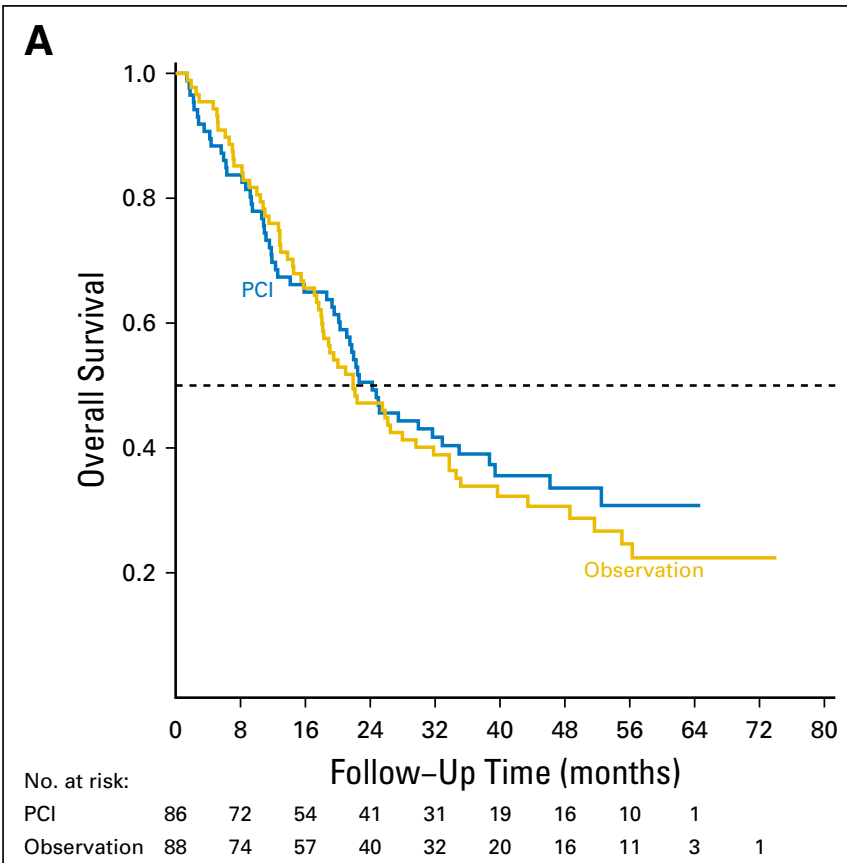

B

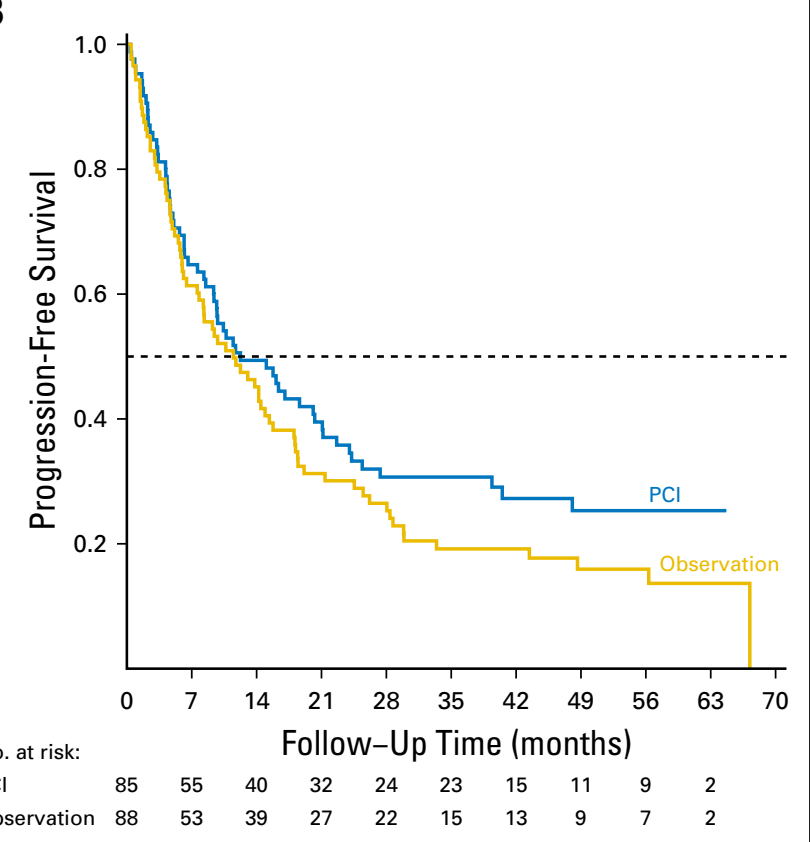

Fig 6. Overall survival and progression-free survival. (A) Overall survival. There is no significant difference in overall survival between the two arms (hazard ratio, 0.9 [95\% $\mathrm{Cl}, 0.62$ to 1.29$]$ ). (B) Progression-free survival. There is no significant difference in progression-free survival between the two arms (hazard ratio, 0.79 [95\% $\mathrm{Cl}, 0.56$ to 1.11 ]). $\mathrm{PCl}$, prophylactic cranial irradiation. 


\begin{tabular}{|c|c|c|c|c|c|c|c|c|c|}
\hline \multirow{3}{*}{$\begin{array}{l}\text { Study or Subgroup } \\
\mathrm{Li}\end{array}$} & \multicolumn{2}{|c|}{ PCl } & \multicolumn{2}{|c|}{ Observation } & \multirow[b]{2}{*}{ Weight, \% } & \multirow{2}{*}{$\begin{array}{c}\text { Risk Ratio } \\
\text { M-H, Fixed, } 95 \% \text { Cl }\end{array}$} & \multirow{2}{*}{\multicolumn{2}{|c|}{$\begin{array}{c}\text { Risk Ratio } \\
\text { M-H, Fixed, } 95 \% \text { Cl }\end{array}$}} & \\
\hline & \multirow{2}{*}{$\frac{\text { Events }}{10}$} & \multirow{2}{*}{$\begin{array}{r}\text { Total } \\
81\end{array}$} & \multirow{2}{*}{$\begin{array}{c}\text { Events } \\
29\end{array}$} & \multirow{2}{*}{$\frac{\text { Total }}{75}$} & & & & & \\
\hline & & & & & 20.5 & $0.32(0.17$ to 0.61$)$ & $\longrightarrow$ & & \\
\hline NVALT-11 & 7 & 87 & 27 & 88 & 18.3 & $0.26(0.12$ to 0.57$)$ & $\longrightarrow-$ & & \\
\hline RTOG 0214 & 13 & 163 & 32 & 177 & 20.9 & $0.44(0.24$ to 0.81$)$ & $\longrightarrow-$ & & \\
\hline RTOG 8403 & 8 & 93 & 18 & 94 & 12.2 & $0.45(0.21$ to 0.98$)$ & & & \\
\hline Total $(95 \% \mathrm{Cl})$ & & 717 & & 745 & 100.0 & $0.33(0.24$ to 0.45$)$ & $>$ & & \\
\hline Total events & 48 & & 149 & & & & & & \\
\hline \multicolumn{5}{|c|}{ Heterogeneity: $\chi^{2}=5.36, \mathrm{df}=6(P=.50) ; 1^{2}=0 \%$} & & 0.01 & 0.1 & 10 & 100 \\
\hline \multicolumn{5}{|c|}{ Test for overall effect: $Z=7.10(P<.001)$} & & & Favors $\mathrm{PCl}$ & Favors $\mathrm{Ob}$ & ion \\
\hline
\end{tabular}

Fig 7. Meta-analysis on the basis of published data from phase III trials on the incidence of brain metastases on the basis of imaging Data from Li et al, ${ }^{10}$ Cox et al, ${ }^{5}$

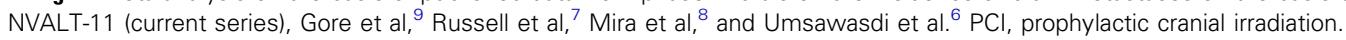

radiotherapy in stage III NSCLC suggest a decrease in the incidence of brain metastases. ${ }^{17}$ If these results are confirmed, the proportion of patients who may experience a beneficial effect from PCI will decrease, whereas, in contrast, PCI may nearly abolish brain metastases.

In conclusion, we show that PCI decreases symptomatic brain metastases with an increase of low-grade AEs, a decrease of QoL only after 3 months, and without affecting OS. We therefore believe that the pros and cons of PCI necessitates a shared decision process between patients and physicians about its use.

\section{AUTHORS' DISCLOSURES OF POTENTIAL CONFLICTS} OF INTEREST

Disclosures provided by the authors are available with this article at jco.org.

\section{AUTHOR CONTRIBUTIONS}

Conception and design: Dirk De Ruysscher, Vincent van der Noort, Harry J.M. Groen

Administrative support: Vincent van der Noort

Provision of study materials or patients: Dirk De Ruysscher, Anne-Marie C. Dingemans, John Praag, Jose Belderbos, Caroline Tissing-Tan, Judith Herder, Tjeerd Haitjema, Fred Ubbels, Frank Lagerwaard, Sherif Y. El Sharouni, Jos A. Stigt, Egbert Smit, Harry J.M. Groen

Collection and assembly of data: Caroline Tissing-Tan, Vincent van der Noort

Data analysis and interpretation: Dirk De Ruysscher, Anne-Marie C. Dingemans, John Praag, Jose Belderbos, Judith Herder, Tjeerd Haitjema, Fred Ubbels, Frank Lagerwaard, Sherif Y. El Sharouni, Jos A. Stigt, Egbert Smit, Harm van Tinteren, Vincent van der Noort, Harry J.M. Groen

Manuscript writing: All authors

Final approval of manuscript: All authors

Accountable for all aspects of the work: All authors

\section{REFERENCES}

1. Vansteenkiste J, De Ruysscher D, Eberhardt $W E$, et al: Early and locally advanced non-small-cell lung cancer (NSCLC): ESMO Clinical Practice Guidelines for diagnosis, treatment and follow-up. Ann Oncol 24:vi89-vi98, 2013 (suppl 6)

2. Sun DS, Hu LK, Cai $Y$, et al: A systematic review of risk factors for brain metastases and value of prophylactic cranial irradiation in non-small cell lung cancer. Asian Pac J Cancer Prev 15:1233-1239, 2014

3. Aupérin $A$, Arriagada $R$, Pignon JP, et al: Prophylactic cranial irradiation for patients with smallcell lung cancer in complete remission. N Engl J Med 341:476-484, 1999

4. Le Péchoux C, Dunant A, Senan S, et al: Standard-dose versus higher-dose prophylactic cranial irradiation $(\mathrm{PCl})$ in patients with limited-stage small-cell lung cancer in complete remission after chemotherapy and thoracic radiotherapy (PCI 99-01, EORTC 22003-08004, RTOG 0212, and IFCT 99-01): A randomised clinical trial. Lancet Oncol 10:467-474, 2009

5. Cox JD, Stanley K, Petrovich Z, et al: Cranial irradiation in cancer of the lung of all cell types. JAMA 245:469-472, 1981
6. Umsawasdi $\mathrm{T}$, Valdivieso $\mathrm{M}$, Chen $\mathrm{TT}$, et al: Role of elective brain irradiation during combined chemoradiotherapy for limited disease non-small cell lung cancer. J Neurooncol 2:253-259, 1984

7. Russell AH, Pajak TE, Selim HM, et al: Prophylactic cranial irradiation for lung cancer patients at high risk for development of cerebral metastasis: Results of a prospective randomized trial conducted by the Radiation Therapy Oncology Group. Int J Radiat Oncol Biol Phys 21:637-643, 1991

8. Mira JG, Miller TP, Crowley JJ: Chest irradiation (RT) vs. chest RT + chemotherapy \pm prophylactic brain RT in localized non-small-cell lung cancer: A Southwest Oncology Group randomized study. Int J Radiat Oncol Biol Phys 19:145, 1990

9. Gore EM, Bae K, Wong SJ, et al: Phase III comparison of prophylactic cranial irradiation versus observation in patients with locally advanced non-small-cell lung cancer: Primary analysis of Radiation Therapy Oncology Group study RTOG 0214. J Clin Oncol 29:272-278, 2011

10. Li N, Zeng ZF, Wang SY, et al: Randomized phase III trial of prophylactic cranial irradiation versus observation in patients with fully resected stage IIIA-N2 non-small-cell lung cancer and high risk of cerebral metastases after adjuvant chemotherapy. Ann Oncol 26:504-509, 2015

11. Pöttgen C, Eberhardt W, Grannass A, et al: Prophylactic cranial irradiation in operable stage IIIA non-small-cell lung cancer treated with neoadjuvant chemoradiotherapy: Results from a German multicenter randomized trial. J Clin Oncol 25:4987-4992, 2007

12. Péchoux CL, Sun A, Slotman BJ, et al: Prophylactic cranial irradiation for patients with lung cancer. Lancet Oncol 17:e277-e293, 2016

13. Peters $S$, Bexelius $C$, Munk V, et al: The impact of brain metastasis on quality of life, resource utilization and survival in patients with non-small-cell lung cancer. Cancer Treat Rev 45:139-162, 2016

14. Li J, Bentzen SM, Renschler $M$, et al: Regression after whole-brain radiation therapy for brain metastases correlates with survival and improved neurocognitive function. J Clin Oncol 25:1260-1266, 2007

15. Tsakonas G, De Petris L, Ekman S: Management of brain metastasized non-small-cell lung cancer (NSCLC): From local treatment to new systemic therapies. Cancer Treat Rev 54:122-131, 2017

16. Hendriks LE, Brouns AJ, Amini M, et al: Development of symptomatic brain metastases after chemoradiotherapy for stage III non-small-cell lung cancer: Does the type of chemotherapy regimen matter? Lung Cancer 101:68-75, 2016

17. Antonia SJ, Villegas A, Daniel D, et al: Durvalumab after chemoradiotherapy in stage III non-smallcell lung cancer. N Engl J Med 377:1919-1929, 2017 


\section{Affiliations}

Dirk De Ruysscher and Anne-Marie C. Dingemans, Maastricht University Medical Center; GROW Research Institute, Maastricht; John Praag, Erasmus University Medical Center, Rotterdam; Jose Belderbos, Egbert Smit, Harm van Tinteren, and Vincent van der Noort, Netherlands Cancer Institute; Frank Lagerwaard, Free University Medical Center, Amsterdam; Caroline Tissing-Tan, Radiotherapy Institute Arnhem, Arnhem; Judith Herder, Antonius Hospital Nieuwegein, Nieuwegein; Tjeerd Haitjema, Medical Center Alkmaar, Alkmaar; Fred Ubbels and Harry J.M. Groen, University of Groningen; University Medical Center Groningen, Groningen; Sherif Y. El Sharouni, University Medical Center Utrecht, Utrecht; Jos A. Stigt, Isala Hospital, Zwolle, The Netherlands; and Dirk De Ruysscher, KU Leuven, Leuven, Belgium.

\section{Support}

Supported by the Dutch Cancer Society (Contract No. AVLZ 2008-4296).

\section{Prior Presentation}

Presented at the 2017 Annual Meeting of the American Society of Clinical Oncology, Chicago, IL, June 2-6, 2017, and the International Association for the Study of Lung Cancer 18th World Conference on Lung Cancer, Yokohama, Japan, October 15-17, 2017.

\section{JCO's GLOBAL REACH}

High-quality, practice-changing content with an Impact Factor in the top $1 \%$ of all journals.

To submit to JCO please visit http://submit.jco.org

TOURNAL OF

CLINICAL

ONCOLOGY
ASCO

AMERICAN SOCIETY OF CLINICAL ONCOLOGY 
Prophylactic Cranial Irradiation Versus Observation in Radically Treated Stage III Non-Small-Cell Lung Cancer: A Randomized Phase III NVALT-11/DLCRG-02 Study

The following represents disclosure information provided by authors of this manuscript. All relationships are considered compensated. Relationships are self-held unless noted. I = Immediate Family Member, Inst = My Institution. Relationships may not relate to the subject matter of this manuscript. For more information about ASCO's conflict of interest policy, please refer to www.asco.org/rwc or ascopubs.org/jco/site/ifc.

Dirk De Ruysscher

Consulting or Advisory Role: Bristol-Myers Squibb (Inst), Genentech (Inst), Merck Serono (Inst), AstraZeneca (Inst), Celgene (Inst)

Research Funding: Bristol-Myers Squibb (Inst)

Anne-Marie C. Dingemans

Consulting or Advisory Role: Genentech (Inst), MSD Oncology (Inst) AstraZeneca (Inst), Pfizer, Eli Lilly (Inst), Boehringer Ingelheim (Inst), Bristol-Myers Squibb, Clovis Oncology (Inst)

\section{John Praag}

No relationship to disclose

\section{Jose Belderbos}

No relationship to disclose

\section{Caroline Tissing-Tan}

Employment: Sirtex Medical (I)

Stock or Other Ownership: Sirtex Medical (I)

Honoraria: Sirtex Medical (I)

\section{Judith Herder}

Consulting or Advisory Role: Roche (Inst), MSD Oncology (Inst), Bristol-Myers Squibb (Inst), AstraZeneca (Inst)

Research Funding: Roche (Inst)

\section{Tjeerd Haitjema}

No relationship to disclose

\section{Fred Ubbels}

No relationship to disclose

Frank Lagerwaard

No relationship to disclose

\section{Sherif Y. El Sharouni}

No relationship to disclose

Jos A. Stigt

No relationship to disclose

\section{Egbert Smit}

Consulting or Advisory Role: Eli Lilly

Research Funding: Boehringer Ingelheim (Inst), Bayer (Inst), Genentech (Inst), AstraZeneca (Inst)

\section{Harm van Tinteren}

No relationship to disclose

\section{Vincent van der Noort}

No relationship to disclose

\section{Harry J.M. Groen}

Consulting or Advisory Role: Pfizer (Inst), Novartis (Inst), AstraZeneca (Inst), Bristol-Meyers Squibb (Inst), MSD Oncology (Inst), Eli Lilly (Inst), AbbVie (Inst), Genentech (Inst)

Research Funding: Eli Lilly (Inst), Roche (Inst) 